\title{
BONE FORMATION BY HETERODIMERS THROUGH NON-VIRAL GENE DELIVERY OF BMP-2/6 AND BMP-2/7
}

\author{
L.D. Loozen ${ }^{1}$, A. Vandersteen ${ }^{1}$, A.H.M. Kragten ${ }^{1}$, F.C. Öner ${ }^{1}$, W.J.A. Dhert² ${ }^{2}$ M.C. Kruyt ${ }^{1}$ and J. Alblas ${ }^{1, *}$ \\ ${ }^{1}$ Department of Orthopaedics, University Medical Centre Utrecht, Utrecht, the Netherlands \\ ${ }^{2}$ Faculty of Veterinary Medicine, Utrecht University, Utrecht, the Netherlands
}

\begin{abstract}
Non-viral gene delivery is a safe technique to release sustained physiologic dosages of bone morphogenetic protein (BMP). Co-delivery of multiple BMPs can result in the formation of more potent BMP heterodimers. In this study, non-viral co-delivery of BMP-2/6 and BMP-2/7, as a means to produce heterodimers, was assessed.

Goat MSCs were non-virally transfected with plasmid DNA encoding BMP isoforms (pBMP) known to be relevant for osteogenesis: BMP-2, -6 or -7 . As a result, BMP-2, -6 and -7 were produced and detectable for up to $14 \mathrm{~d}$ and their combined delivery (pBMP-2 with pBMP-6 or pBMP-7) was used to create BMP-2/6 and BM-2/7 heterodimers. Formation and secretion of the heterodimer proteins was validated by sandwich enzyme-linked immunosorbent assay (ELISA). Produced BMPs and heterodimers were biologically active, as confirmed by differentiation of reporter cells and MSCs. To assess bone formation, transfected MSCs were seeded on to ceramic scaffolds and implanted subcutaneously into nude mice. Bone formation was significantly enhanced in the pBMP-2/6 condition and a trend for more bone formation was observed in the pBMP-2/7 and pBMP-6 homodimer condition. No bone was found in the pBMP-2, pBMP-7 or control condition.

In conclusion, simultaneous delivery of pBMP-2 with pBMP-6 or -7 resulted in the production of heterodimers that were beneficial for bone formation as compared to BMP homodimers. Combination of BMP sequences could reduce the need for high BMP protein dosages and might enhance prolonged availability of the growth factors.
\end{abstract}

Keywords: Heterodimers, bone morphogenetic protein, non-viral gene delivery, bone regeneration.

*Address for correspondence: J. Alblas, PhD, Department of Orthopaedics, University Medical Centre Utrecht, Room G05.228, Heidelberglaan 100, 3584 CX, Utrecht, the Netherlands.

Telephone: +31 (0)887551122Ｆax:+31(0)302510638Ｅmail: j.alblas@umcutrecht.nl

Copyright policy: This article is distributed in accordance with Creative Commons Attribution Licence (http://creativecommons.org/licenses/by-sa/4.0/).

\section{Introduction}

Autologous bone grafting is frequently performed in cases of both non-union and spinal fusion surgery. Although autologous bone is the best grafting material, only limited amounts are available and harvesting is associated with local morbidity (Papakostidis et al., 2008). Therefore, other strategies to induce bone formation and regeneration are being explored. These strategies focus on the delivery of the different components involved in bone regeneration, such as (pro)osteogenic cells, calcium phosphatebased scaffold materials and growth factors.

Multipotent stromal cell (MSC)-based approaches to repair bone tissue are effective in small and large animal models (Asatrian et al., 2015). However, the exact role of MSCs is not fully elucidated, as the few cell-tracing studies available show contradictory results with respect to long-term engraftment, albeit a cell-dependent performance of the implants is often apparent (Becquart et al., 2012; Kruyt et al., 2008). This has led to the theory that at least part of the pro-osteogenic effect of MSCs lies in the temporary excretion of factors beneficial for bone regeneration (Dupont et al., 2010; Grayson et al., 2015). This property may be utilised even further by genetically modifying seeded cells to overexpress pro-osteogenic proteins (Evans and Huard, 2015).

Interesting candidates are bone morphogenetic proteins (BMPs) isotypes, as they play an important role in bone formation (Kang et al., 2004). To date, at least 20 isotypes of BMPs are identified in mammals, among which BMP-2 and BMP-7 are the best known and clinically approved (Bishop and Einhorn, 2007; Gautschi et al., 2007). Other BMPs also show potential for bone regeneration (Kang et al., 2004), among those BMP-6, which is related to both chondrogenesis and osteogenesis (Kayabasi et al., 2013; Vukicevic 
and Grgurevic, 2009). Besides these well-known homodimeric BMPs, there is evidence for the existence of BMP heterodimers (Little and Mullins, 2009; Mueller and Nickel, 2012). Heterodimers such as BMP-2/6 (Valera et al., 2010) and BMP-2/7 (Morimoto et al., 2015) have been produced in vitro. Compared to their homodimeric counterparts, heterodimers show increased activity (Isaacs et al., 2010; Israel et al., 1996; Morimoto et al., 2015; Zhu et al., 2004).

Despite their high potency in inducing bone formation, BMP-based therapies are hampered by short protein half-life and quick degradation in vivo (Geiger et al., 2003; Poynton and Lane, 2002). Non-viral delivery of BMP-encoding sequences to cells/tissue could overcome this drawback, as this strategy ensures a transient, sustained protein release. Furthermore, non-viral methods are less immunogenic and safer than viral approaches (Gaspar et al., 2015). However, the major drawback of non-viral methods is the low in vivo transfection efficiency (Osawa et al., 2010). This could be circumvented by combining gene delivery with cellbased regeneration: donor cells, harvested during surgery (Virk et al., 2011) or received from a donor bank (Sanz et al., 2012), can be efficiently transfected ex vivo to overexpress BMP before implantation (Dickens et al., 2010). Co-delivery of multiple BMPs can enhance even more the potency of cell-based gene delivery strategies (Feichtinger et al., 2014; Kawai et al., 2009; Zhu et al., 2004). Nucleofection is an efficient electro-permeabilisation method for delivering plasmid DNA into both primary cells and established cell lines. The high transfection efficiency of nucleofection relates to prolonged protein expression and production of osteogenic factors and results in bone formation in vivo (Mizrahi et al., 2013; Sheyn et al., 2008).

In this study, the ex vivo non-viral gene delivery of BMP-2/6 and BMP-2/7 into MSCs for producing heterodimers was assessed. Subsequently, the capacity to induce osteogenic differentiation and bone formation was assessed and compared to gene delivery of single BMP isotypes.

\section{Materials and Methods}

\section{Isolation and culture of goat MSCs}

After approval of the local animal care committee, bone marrow was aspirated from adult female Dutch milk goats, 24-27 months old, weighting 50-60 kg. MSCs were isolated by adherence to tissue culture plastic and cultured in normal expansion medium, consisting of $\alpha$-modified minimum essential medium ( $\alpha$-MEM; Gibco), $10 \%$ (v/v) foetal bovine serum (FBS; Hyclone), $100 \mathrm{U} / \mathrm{mL}$ penicillin, $100 \mathrm{mg} / \mathrm{mL}$ streptomycin and $2 \mathrm{mM}$ L-glutamine (Glutamax; Gibco). MSCs were maintained at $37{ }^{\circ} \mathrm{C}$ and $5 \%$ $\mathrm{CO}_{2}$ in a humidified incubator. The osteogenic, chondrogenic and adipogenic differentiation potential of the MSCs was determined using appropriate media, as described in detail previously (Geuze et al., 2009). MSCs were cryopreserved and used between passage 4 and 6. MSCs from different goat donors were used for the in vitro experiments. For the in vivo experiment, cells from a single donor were used for transplantation into nude mice. Goat MSCs were chosen because they are well characterised and can be applied in future translational goat studies. These cells were characterised for their osteogenic differentiation capacity in vitro and cryopreserved according to an established protocol (Kruyt et al., 2004).

\section{Vector composition}

The vectors used were pEGFP-N1 (BD Biosciences) and pVAX1 (Invitrogen) as such or sub-cloned to contain full-length recombinant human (rh) BMP2 (using HindIII and BamHI restriction sites) or rhBMP-7 (using HindIII and NotI restriction sites), with the resulting products designated as pBMP-2 and pBMP-7. pcDNA3.1 (Invitrogen), containing the mouse BMP-6 cDNA (NM_007556) inserted using the HindIII and XhoI restriction sites, was kindly provided by Prof. Peter ten Dijke, Leiden University Medical Centre, Leiden, the Netherlands. This construct was referred to as pBMP-6. Expression of each of the BMP isoforms was driven by the cytomegalovirus (CMV) promoter. The murine BMP6 sequence is very similar to the human isoform, with only a 2 amino acids difference in the 7-cysteine region and 5 differences in the basic amino-terminal domain; overall amino acid identity is $91 \%$. A comparison of vectors containing human or rodent BMP-6 demonstrates identical osteogenic activities in rat models (Li et al., 2006). All plasmid DNA construct sequences were confirmed by sequencing. Plasmid DNA was isolated, purified and cleared from endotoxins (EndoFree Plasmid Maxi kit, Qiagen K.K., Tokyo, Japan) prior to cell and animal studies.

\section{Gene delivery by nucleofection}

With the aid of Amaxa Nucleofector ${ }^{\mathrm{TM}}$ technology (Lonza), MSCs were transfected with the different vectors, according to the manufacturer's instructions. Immediately after electroporation, the cells were transferred to tissue culture plates containing expansion medium supplemented with 20 \% FBS. Nucleofected MSCs were harvested by addition of trypsin-ethylenediaminetetraacetic acid (EDTA) at least $24 \mathrm{~h}$ after gene transfer. Living and dead cells in culture medium, washing and trypsin steps were collected and analysed during the optimisation period. Viability and transfection efficiency were assessed by staining for $30 \mathrm{~min}$ on ice with $10 \mu \mathrm{g} /$ mL 7-aminoactinomycin D (7-AAD) (SigmaAldrich) in phosphate-buffered saline (PBS) and analyses of enhanced green fluorescent protein (EGFP) expression using Gallios Flow Cytometer (Beckman Coulter) and FlowJo software (FlowJo Inc., 
Ashland, OR, USA). The percentage of GFP-positive cells within the gated living cells and their mean fluorescence intensity was determined.

The different parameters of the nucleofection protocol were optimised in the goat MSCs using the pEGFP-N1 vector. 6 different buffers were compared, as follows: buffer $1\left[5 \mathrm{mM} \mathrm{KCl}, 15 \mathrm{mM} \mathrm{MgCl}_{2}, 120 \mathrm{mM}\right.$ $\mathrm{Na}_{2} \mathrm{HPO}_{4} / \mathrm{NaH}_{2} \mathrm{PO}_{4}$ (pH 7.2), $50 \mathrm{mM} \mathrm{NaCl}$; buffer 2 [ $5 \mathrm{mM} \mathrm{KCl}, 15 \mathrm{mM} \mathrm{MgCl}, 15 \mathrm{mM}$ 4-(2-hydroxyethyl)1-piperazineethanesulphonic acid (HEPES), $150 \mathrm{mM}$ $\mathrm{Na}_{2} \mathrm{HPO}_{4} / \mathrm{NaH}_{2} \mathrm{PO}_{4}$ ( $\mathrm{pH}$ 7.2), $50 \mathrm{mM} \mathrm{NaCl}$; buffer 3 [5 $\mathrm{mM} \mathrm{KCl}, 15 \mathrm{mM} \mathrm{MgCl}, 15 \mathrm{mM}$ HEPES, $90 \mathrm{mM}$ $\mathrm{NaCl}, 10 \mathrm{mM}$ glucose, $0.4 \mathrm{mM} \mathrm{Ca}\left(\mathrm{NO}_{3}\right)_{2}, 40 \mathrm{mM}$ $\mathrm{Na}_{2} \mathrm{HPO}_{4} / \mathrm{NaH}_{2} \mathrm{PO}_{4}$ (pH 7.2)]; buffer 4 [OptiMEM]; buffer 5 [Nucleofector solution ${ }^{\mathrm{TM}}$ (Lonza)/OptiMEM $(1: 1 \mathrm{v} / \mathrm{v})]$; buffer 6 [Nucleofector solution ${ }^{\mathrm{TM}}($ Lonza)]. Subsequently, 6 different nucleofection programs were compared (G22, U28, U23, T30, X01, X05), which were recommended in the preliminary protocol provided by Amaxa Nucleofector ${ }^{\mathrm{TM}}$ technology (Lonza) and previously reported in the literature (Aslan et al., 2006; Flanagan et al., 2012). Protocols differed in intensity and length of the electric pulse (field strength). The concentration of plasmid DNA (pDNA) was optimised using 2, 5, 10, 15, 20 and $40 \mu \mathrm{g}$ of pDNA per reaction (in a total volume of $100 \mu \mathrm{L}$ ). Cell density varied among $0.5,1,2,4$ and $8 \times 10^{6}$ cells per reaction.

\section{In vitro BMP protein production}

$2 \times 10^{6}$ MSCs were transfected with pBMP-2, pBMP-6, pBMP-7, $1: 1$ combinations of pBMP-2/-6 and pBMP$2-/ 7$ and empty vector (total amount of $20 \mu \mathrm{g}$ of $\mathrm{pDNA}$ per reaction), according to the nucleofection protocol, using buffer 1 and program G22. Cells were kept for $24 \mathrm{~h}$ in expansion medium supplemented with $20 \%$ FBS, then the medium was replaced with normal expansion medium and cells were cultured for up to 2 weeks. Media samples from the nucleofected MSCs were collected at day 1, 2, 4, 7 and 14. Production of BMP-2,- 6, -7 homodimers and BMP-2/6 and -2/7 heterodimers was assessed using a commercially available enzyme-linked immunosorbent assay (ELISA) kits (BMP-2: PeproTech Ltd. London, UK; BMP-6 and 7: Duo-Set ELISA Development kit, R\&D Systems, Inc., Minneapolis, MN, USA). All ELISAs kits detected both human and mouse BMP and showed high cross reactivity between species, such as goat BMP, due to the highly conserved BMP amino acid sequences. Endogenous BMP production by the goat MSCs was detected, but it might have been underestimated due to possible lesser activity.

\section{In vitro heterodimer experiment}

To assess the presence of BMP-2/6 and $-2 / 7$ heterodimers, a sandwich ELISA was performed using the anti-BMP- 6 or -7 capture antibodies and anti-BMP-2 detection antibody. Media samples from MSCs transfected with pBMP-2, $-6,-7,-2 / 6,-2 / 7$ or empty vector were collected $2 \mathrm{~d}$ after transfection and added into duplicate wells of the ELISA plates coated with capture antibody. Calibration curves were performed with recombinant BMP-2/6 and -2/7 (R\&D Systems Inc., Minneapolis, MN, USA). Duplicate control samples with $4 \mathrm{ng} / \mathrm{mL}$ recombinant BMP-2, -6, -7 (R\&D Systems Inc.) were used to establish possible cross-reactivity of the antibodies. Subsequently, antiBMP-2 antibody was used for detection.

\section{Bioactivity assay of secreted transgene products}

The bioactivity of BMPs, secreted by MSCs transfected with BMP-2, -6, -7, -2/6, -2/7 and empty vector, was determined using mouse chondrogenic ATDC-5 reporter cells, which express alkaline phosphatase (ALP) upon exposure to a variety of BMPs (Nakajima et al., 2009). Cell medium was harvested $48 \mathrm{~h}$ after nucleofection and added in duplicate to subconfluent ATDC-5 cells. Parallel positive controls, consisting of a range of increasing concentrations ( 0 to $250 \mathrm{ng} / \mathrm{mL}$ ) of rhBMP-2, 6 and 7, were included. $3 \mathrm{~d}$ after the addition of the conditioned medium or fixed amounts of rhBMP protein, cells were lysed in PBS containing $0.5 \%$ Triton X-100. ALP activity was determined using a colorimetric assay kit (Abcam), with p-nitrophenyl phosphate (pNPP) as substrate. The assay was performed in duplicate and the enzyme activity was expressed as $\mathrm{U} / \mathrm{mL}$, relative to the empty vector control.

\section{Osteogenic differentiation of MSCs overexpressing BMPs}

MSCs overexpressing different BMPs or combinations of BMPs were assayed for induction of osteogenicity. After transfection and medium refreshment at day 1 , cells were placed in expansion medium supplemented with $5 \mathrm{mM}$ L-ascorbic acid-2-phosphate (AsAP) and $10 \mathrm{mM} \beta$-glycerophosphate ( $\beta \mathrm{GP})$ for 10 or $20 \mathrm{~d}$ to assess early (ALP) and late (mineralisation) osteogenic differentiation, respectively. The medium was refreshed every $4 \mathrm{~d}$. DNA analysis was performed using Picogreen kit (Quant-iT PicoGreen dsDNA Reagent Kit, Fisher Scientific). ALP activity was expressed as $\mathrm{U} / \mathrm{mL}$, normalised to DNA content, relative to the empty vector control. Alizarin red staining was performed to evaluate mineralisation in the differentiated conditions. The cells were washed with PBS, fixed in cold $10 \%$ formaldehyde and rinsed with distilled water. After being washed, staining was performed with alizarin red solution $(2 \% \mathrm{w} / \mathrm{v}$, $\mathrm{pH} 4.2$ ) for $10 \mathrm{~min}$, followed by extensive washing with distilled water to remove the remaining stain.

\section{Construct composition of in vivo implants}

6 different constructs, comprising a $3 \times 3 \times 6 \mathrm{~mm}$ porous biphasic calcium phosphate ceramic scaffolds (BCP, Xpand biotechnology BV, Bilthoven, the Netherlands), were prepared. This material is composed of $80 \pm 5 \%(\mathrm{w} / \mathrm{v})$ hydroxyapatite and $20 \pm 5 \%(\mathrm{w} / \mathrm{v}) \beta$-tricalcium phosphate and has a porosity of $70 \pm 5 \%$, with a pore size of $200-800 \mu \mathrm{m}$ (Loozen et al., 2015; Loozen et al., 2013). The scaffolds were seeded with $0.5 \times 10^{6}$ goat MSCs transfected with 
$20 \mu \mathrm{g}$ BMP-encoding plasmid DNAs or control vector as follows: empty vector, $\mathrm{pBMP}-2,-6,-7,-2 / 6$ or $-2 / 7$. After nucleofection, the MSCs were kept in expansion medium for $1 \mathrm{~h}$, then counted, pelleted and seeded on the ceramic scaffolds $1 \mathrm{~d}$ prior to implantation.

\section{Ectopic transplantation of nucleofected MSCs}

Experiments were conducted with the permission of the local Ethical Committee for Animal Experimentation and in compliance with the Institutional Guidelines on the use of laboratory animals. Ten female nude non-obese diabetic/severe combined immunodeficiency (NOD/SCID) mice (Hsd-cpb:NMRI-nu, Harlan) were anaesthetised with $1.5 \%$ isoflurane. 5 separate subcutaneous dorsal pockets per animal were created in which implants were placed in a randomised manner ( $n=10$ for pBMP-2/6, $-2 / 7$ and empty control; $n=7$ for pBMP-2 and BMP-7 and $n=6$ for BMP- 6 ). The incisions were closed using a Vicryl 5-0 suture. The animals were treated postoperatively with subcutaneous injection of $0.05 \mathrm{mg} / \mathrm{kg}$ analgesic buprenorphine (Temgesic, Schering-Plough, Utrecht, the Netherlands) and housed together at the Utrecht University animal laboratory. 3 weeks after implantation, $10 \mathrm{mg} / \mathrm{kg}$ calcein green was administered subcutaneously (Sigma-Aldrich). At 4 weeks after implantation, $30 \mathrm{mg} / \mathrm{kg}$ alizarin red was administered subcutaneously (Merck) (van Gaalen et al., 2010). The mice were euthanised after 5 weeks and the constructs were retrieved.

\section{Explantation and processing}

After retrieval, each sample was cut in half to analyse general morphology, transgene expression and bone histology. One half was fixed overnight in $4 \%$ (v/v) formalin, decalcified in 0.36 M EDTA ( $\mathrm{pH} 7.4$ ), processed through alcohol dehydration series and cut into $5 \mu \mathrm{m}$-thick paraffin sections. The other half was fixed in $4 \%$ formalin, dehydrated by ethanol series and embedded in polymethylmethacrylate (Sigma-Aldrich). $30 \mu \mathrm{m}$-thick sections were cut from the centre and side of each implant using a sawing microtome (Leica). Half of the sections were stained with basic fuchsin/methylene blue. High-resolution digital images of the $3^{\text {rd }}$ and $7^{\text {th }}$ section were acquired. Adobe Photoshop CS5 was used to pseudo-colour the bone scaffold areas, hereafter bone area percentage [bone area $\%=$ bone area/(total area - scaffold area) $\times 100 \%$ ] was determined. Unstained sections were kept for fluorochrome analysis. A fluorescence microscope (Olympus BX51), equipped with a quadruple filter block (XF57, dichroic mirror 400, 485, 558 and $640 \mathrm{~nm}$; Omega filters), was used to determine fluorochrome incorporation at several time points during the study.

\section{BMP-2 and BMP-7 immunohistochemistry}

BMP-2 and BMP-7 detection was performed on paraffin sections rehydrated, permeabilised with $0.1 \%$ Triton X-100 in PBS and incubated in $0.3 \%$ (v/v) $\mathrm{H}_{2} \mathrm{O}_{2}$ for $10 \mathrm{~min}$. Antigen retrieval steps were performed in $10 \mathrm{mM}$ sodium citrate buffer ( $\mathrm{pH}$ 6.0) for $30 \mathrm{~min}$ at $95^{\circ} \mathrm{C}$. Then, the sections were blocked in $5 \%(\mathrm{w} / \mathrm{v})$ bovine serum albumin (BSA) in PBS for $30 \mathrm{~min}$ and subsequently incubated for $2 \mathrm{~h}$ at room temperature with $2.5 \mu \mathrm{g} / \mathrm{mL}$ rabbit-anti-human BMP2 (C43125; LifeSpan BioSciences, Nottingham, UK) or $2 \mu \mathrm{g} / \mathrm{mL}$ rabbit-anti-human BMP-7 (ab56023; Abcam) in PBS $/ 5 \%$ BSA. Negative control labellings were performed with 2.5 and $2 \mu \mathrm{g} / \mathrm{mL}$ non-immunised rabbit IgG in PBS (X0903; Dako). Subsequently, samples were incubated with $1 \mu \mathrm{g} / \mathrm{mL}$ goat antirabbit horseradish peroxidase (P0448; Dako) in $\mathrm{PBS} / 5 \% \mathrm{BSA}$ for $60 \mathrm{~min}$ at room temperature. The staining was developed with 3,3'-diaminobenzidine (DAB). Counterstaining was performed with Mayer's haematoxylin.

\section{Statistics}

SPSS version 20 (IBM SPSS, Inc.) software was used for statistical analyses, significance was assumed when $p<0.05$. Levene's test was used to assess the equality of variances of in vitro data (Fig. 1, 2, 3, 4 and 5). A square root data transformation was performed on the data of Fig. 2 and 4. ANOVA with Tukey correction for post-hoc analysis was performed to assess differences between conditions. Kruskal-Wallis test by ranks was performed on the data in Fig. 3a, as the data were not normally distributed (based on the observation of skewed data and a significant ShapiroWilk test). For in vivo scoring of bone incidence (Fig. 6a), the Fisher exact test was used to examine whether the incidence of bone was random within the control, pBMP-2/6 and pBMP-2/7 condition. Post-hoc pairwise comparison of these conditions was applied using a Bonferroni correction. The data of the in vivo bone area percentage (Fig. 6b) were not normally distributed. A Friedman test was performed, with a randomised block design only for the pBMP-2/6, pBMP-2/7 and control conditions. Post-hoc pairwise comparison of $\mathrm{pBMP}-2 / 6$ and $\mathrm{pBMP}-2 / 7$ conditions to the control was performed with a Wilcoxon signed rank test with Bonferroni correction. Data are presented as mean \pm standard deviation (SD).

\section{Results}

\section{Optimisation of transgene expression by MSCs}

To examine the efficiency of non-viral gene delivery into MSCs, Amaxa Nucleofector ${ }^{\mathrm{TM}}$ technology (Lonza) was used for delivery of the EGFP gene into MSCs. Settings and reagents for the nucleofection were optimised through a stepwise approach. 6 buffers were compared, consisting of 1 provided by the manufacturer and 5 suggested in the literature. Buffer 1 resulted in transfection efficiency and viability of $65 \pm 9 \%$ and $34 \pm 12 \%$, respectively, whereas the recommended buffer 6 resulted in $72 \pm 8 \%$ and $26 \pm 9 \%$. Buffer 1 was chosen for further experiments because of its known composition, compared to the 


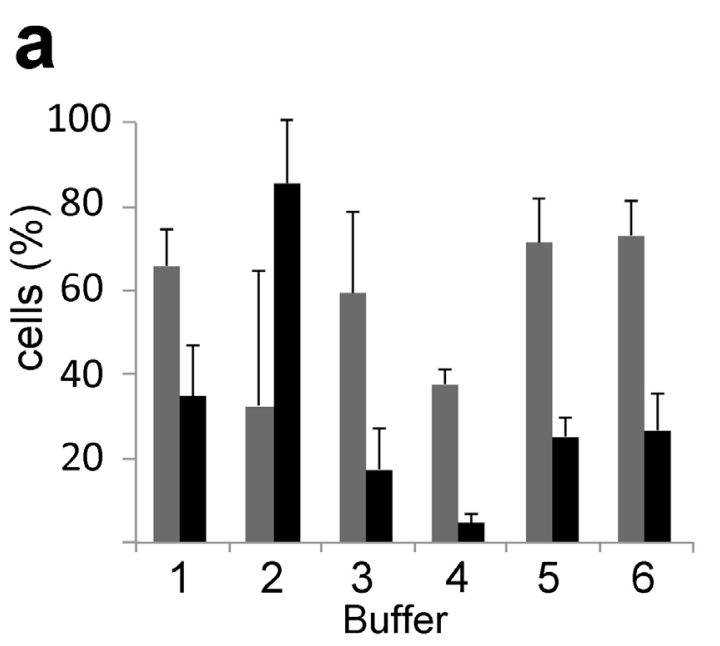

b
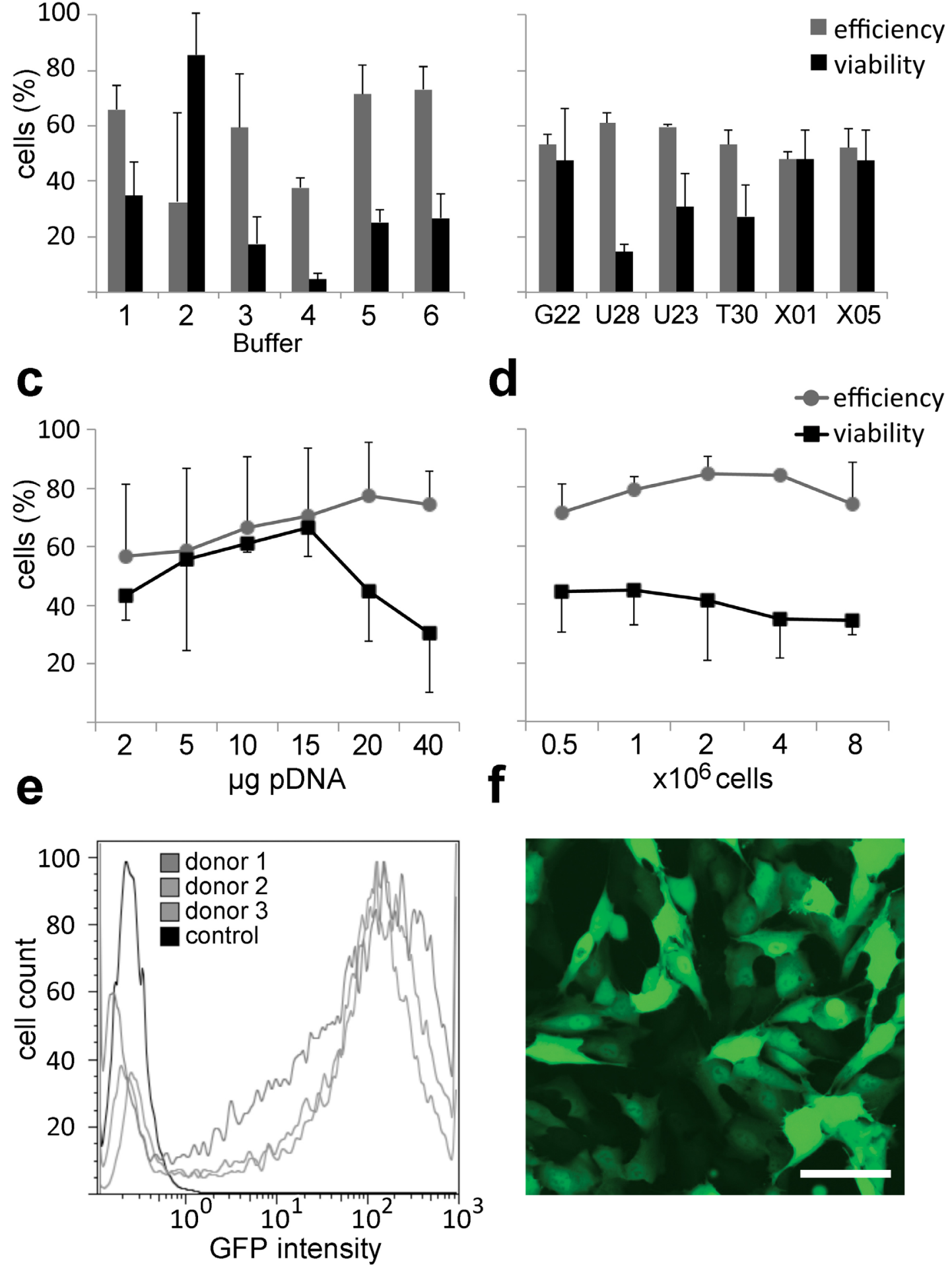

Fig. 1. Optimisation of nucleofection considering cell viability and transfection efficiency. (a) Different nucleofection buffers, with nucleofection program U23, $5 \times 10^{5}$ cells and $5 \mu \mathrm{g}$ pEGFP-N1. (b) Different nucleofection programs, with nucleofection buffer $1,5 \times 10^{5}$ cells and $5 \mu \mathrm{g}$ pEGFP-N1. (c) Different pDNA concentrations, with nucleofection buffer 1, program G22 and $5 \times 10^{5}$ cells. (d) Different cell density, with nucleofection buffer 1, program G22 and $20 \mu \mathrm{g}$ pEGFP-N1. (e) Cells expressing GFP were measured by flow cytometry and compared to MSCs-mock (cells that underwent nucleofection without DNA) (buffer 1, program G22, $20 \mu \mathrm{g}$ of pDNA and $1 \times 10^{6}$ cells). (f) Fluorescence microscopy of monolayer cells at day 1. Scale bar $=50 \mu \mathrm{m}$. Duplicate measurements were assessed from three different donors (mean $\pm \mathrm{SD}$ ). $a$ significantly higher than all other conditions. $b$ significantly lower than buffer 1,5 and 6. $c$ significantly lower than all other conditions. $d$ significantly higher than X01 and X05. $e$ significantly lower than G22, X01 and X05. $f$ significantly lower than X01 and X05. $g$ significantly higher than the condition with $40 \mu \mathrm{g}$. 
Amaxa buffer 6, and high transfection viability and efficiency (Fig. 1a). Subsequently, nucleofection programs were assessed. Programs were either suggested by the manufacturer or derived from the literature. Programs differed in intensity and length of the electric pulse applied (details are proprietary information of Lonza). Program G22 (transfection efficiency: $53 \pm 3 \%$; transfection viability: $48 \pm 19 \%$ ) was considered optimal, although program X01
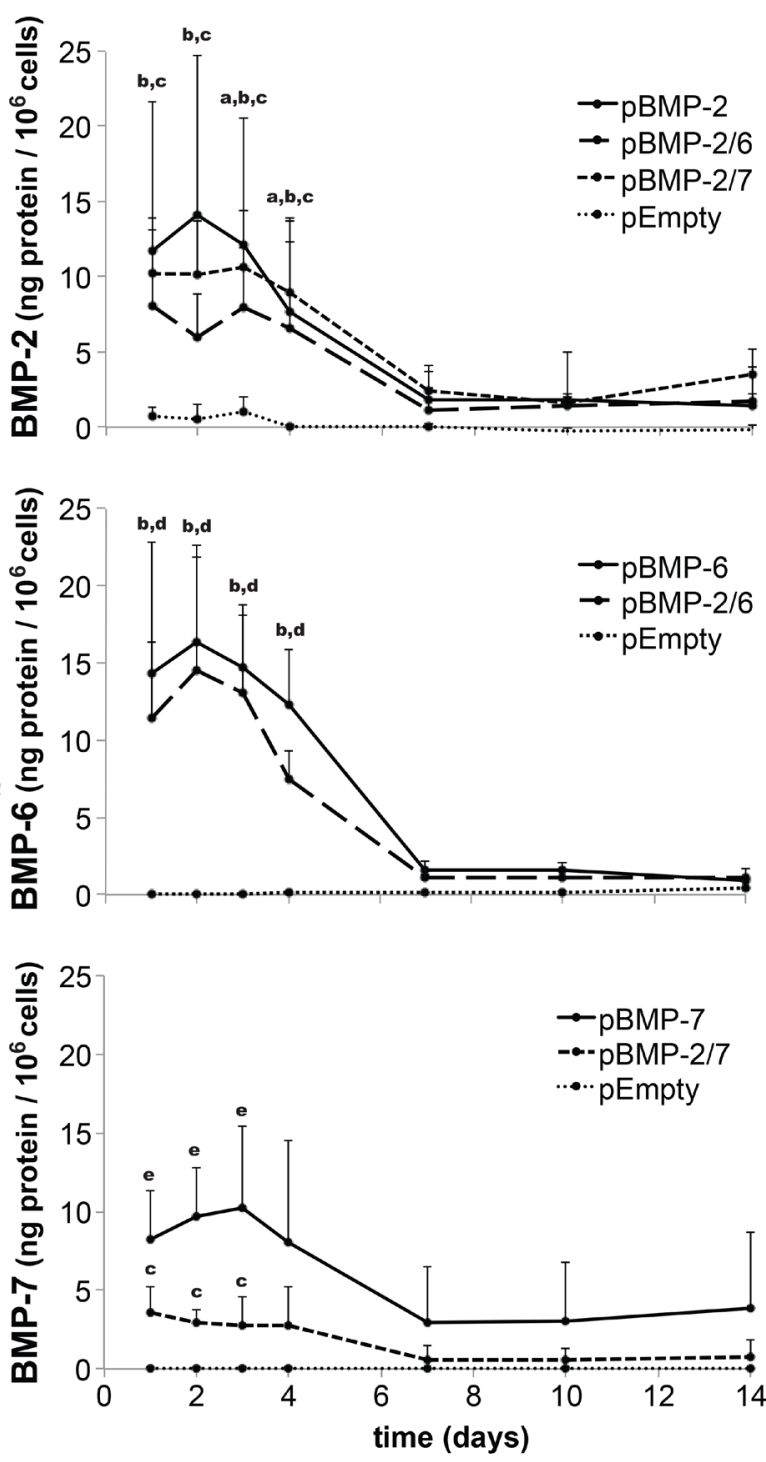

Fig. 2. Secretion of rhBMP-2 and rhBMP-7 from nucleofected MSCs. Cumulative BMP-2, -6 and -7 release from MSCs overexpressing BMPs. Medium was changed after $4 \mathrm{~d}$. When assessing overall BMP production, a peak could be observed between day 2 and 3, followed by a gradual protein production decrease. Control conditions showed negligible BMP2, -6 and -7 levels. The co-delivery of pBMP-2/6 and pBMP-2/7 resulted in BMP production, likely of both homo- and heterodimers. Duplicate measurements were assessed from 3 different donors (mean \pm SD). Significant differences as follows: BMP-2 expression was higher in (a) pBMP-2, (b) pBMP-2/6, (c) pBMP$2 / 7,(d)$ pBMP-6 and (e) pBMP-7 conditions than in pEmpty. and X05 gained similar results (Fig. 1b). Thereafter, pDNA concentrations were assessed. The condition with $20 \mu \mathrm{g}$ of pEGFP-N1 resulted in the highest incidence of gene-expressing cells (77 $\pm 19 \%$ ), with still acceptable viability (45 $\pm 17 \%$ ) (Fig. 1c). Finally, the number of cells per reaction was varied. No evident changes in viability or transfection efficiency were observed by increasing the number of cells per reaction (Fig. 1d).

\section{In vitro BMP production}

ELISAs were performed on media collected from cultures of nucleofected cells to assess the extent of BMP-2, -6 and -7 secretion as a result of pBMPs overexpression. BMP protein production was higher in cells overexpressing the BMP coding sequence than in control cells. Endogenous expression levels of BMP- 6 and BMP-7 in the control were below the detection limit of the ELISA. Some endogenous BMP2 was detected $(<2 \mathrm{ng} / \mathrm{mL}$, up to day 3$)$, which could have been underestimated due to reduced reactivity with goat BMP-2 as compared to human BMP-2. In the pBMP conditions, the highest levels of BMP were determined at day 2 or 3 after transfection and measured for pBMP-2, -6 and $-7: 14 \pm 11,16 \pm 5$ and $16 \pm 6 \mathrm{ng} / 10^{6}$ cells, respectively. At day 4 , medium was refreshed, thereafter BMP concentrations were lower. As expected, co-delivery of pBMP-2/6 and pBMP2/7 resulted in decreased production of each BMP isotype, which was most evident in the BMP-7 ELISA. The ELISA kits used detected both homodimers and heterodimers (Fig. 2).

\section{Co-delivery of BMPs resulted in heterodimer formation}

To ascertain the presence of heterodimers upon codelivery of combinations of BMPs, sandwich ELISAs were performed using anti-BMP-6 (Fig. 3a) or antiBMP-7 (Fig. 3b) capture antibodies and anti-BMP-2 detection antibody. Controls comprised recombinant BMP-2, -6 and -7 homodimers. In both sandwich ELISAs, the anti-BMP-6 and -7 capture antibodies showed some cross reactivity with recombinant BMP-2, which was estimated to be less than 10-20\% of the total signal. Instead, the anti-BMP-2 antibody was specific. Co-delivery of pBMP-2 and -6 , as well as pBMP-2 and -7, resulted in higher heterodimer values than the homodimer conditions, with pBMP-2/7 condition being significantly higher than the $\mathrm{pBMP}-$ 2 and pBMP-7 conditions (Fig. 3b). No statistically significant differences were detected for the pBMP2/6 condition as compared to the other pBMP conditions. Almost no heterodimers were detected in one donor, but the other two donors showed high ELISA values that could not be found in the pBMP-2 and pBMP-6 conditions (Fig. 3a). Therefore, it was confident to assume that BMP-2/6 heterodimers were formed. The exact amount of heterodimers and homodimers formed could not be determined due to some cross reactivity. 


\section{Bioactivity of BMPs on producer cells and reporter cells}

Protein bioactivity was assessed with ATDC-5 reporter cells, which differentiate upon stimulation with BMPs by producing ALP as an early osteogenic differentiation marker (Nakajima et al., 2009). Positive controls with rhBMP-2, -6 and -7 were included. A significant ALP increase was found in both co-delivery conditions. Similar trends could be observed for the transfection with single conditions, although not significant (Fig. 4). In consecutive experiments it was found that MSCs were still capable of differentiation after transfection. $10 \mathrm{~d}$ after nucleofection and incubation in their own produced BMP, ALP produced by MSCs was significantly higher in conditions with co-delivery of pBMP-2/6 and $\mathrm{pBMP}-2 / 7$ than in the single transfections (Fig. $5 a)$. These results agreed with the results of the alizarin red staining performed on day 20 , showing increased mineralisation in the co-delivery conditions as compared to the pBMP-2 and pBMP-6 single transfections (Fig. 5b).

\section{Bone formation and immunological aspects of the implants}

To assess the effectiveness of BMP heterodimers with respect to bone formation, transfected MSCs were seeded on ceramic scaffolds and implanted subcutaneously in mice for 5 weeks. 1 animal died postoperatively, possibly due to perioperative hypothermia. The other animals fulfilled the implantation period without complications. Microscopic analysis revealed tissue ingrowth with connective tissue throughout all scaffolds. Distinct differences in cell morphology or cell density were not found (Fig. 7). Bone was present in the pBMP$2 / 6$, pBMP-2/7 and pBMP- 6 conditions. No bone was found in the pBMP-2, pBMB-7 or control condition (Fig. 6a). The incidence of bone was not randomly distributed over the conditions (Fisher exact test: $p<0.001)$. When assessing individual groups, no significant difference in incidence was found. Histomorphometry showed bone area percentage of $1.8 \pm 1.8 \%, 1.7 \pm 2.8 \%$ and $0.15 \pm 0.4 \%($ mean \pm SD $)$ in $\mathrm{pBMP}-2 / 6, \mathrm{pBMP}-2 / 7$ and $\mathrm{pBMP}-6$ conditions, respectively. Statistical analysis was only performed on the pBMP-2/6, pBMP-2/7 and control condition $(n=9)$ due to the loss of 1 animal, resulting in $n=5$ for the other conditions. Bone area percentage was significantly higher in the pBMP-2/6 condition as compared to control (Fig. 6b). Fluorochrome markers showed that bone formation started before week 3 in most of the cases, which was not associated with a specific condition (results not shown).

\section{BMP production in implants as a result of gene therapy}

BMP-2 and BMP-7 immunohistochemistry was performed to detect the presence of the BMPs and localise the producing cells in vivo. The antibodies used were human-specific but, because of highly conserved sequences, cross-reactive with endogenous

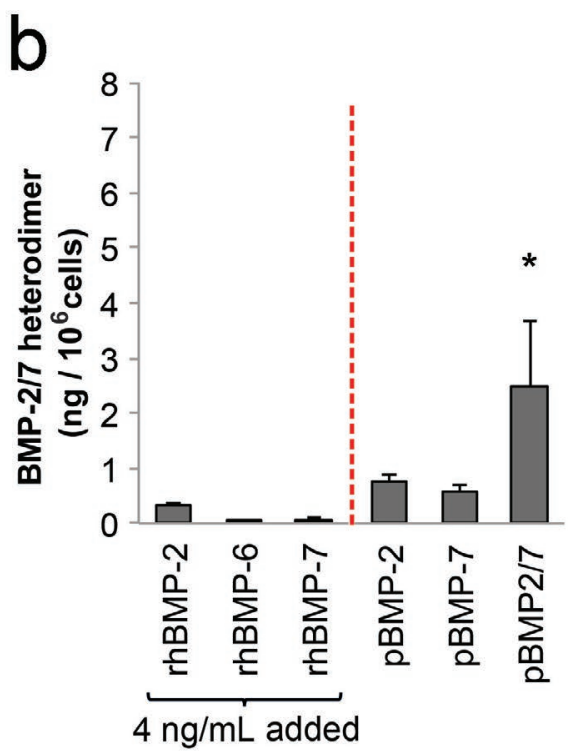

Fig. 3. Heterodimer formation through co-delivery of pBMP-2 with pBMP-6 or pBMP-7. ELISA sandwiches were performed on the medium of MSCs overexpressing a single or two BMP isotypes (day 2 after transfection) using (a) anti-BMP-6 or (b) anti-BMP-7 capture antibodies and anti-BMP-2 detection antibody. Calibration curves were prepared with recombinant BMP-2/6 and BMP-2/7 heterodimers, respectively. Controls, comprising rhBMP-2, -6 and -7 homodimers, are shown on the left. BMP- 2 was recognised by anti-BMP-6 and anti-BMP-7 capture antibodies, although at low affinity; whereas BMP-6 and BMP-7 were not recognised by the anti-BMP-2 antibody. The ELISA sandwiches in $\mathbf{a}$ and $\mathbf{b}$ detected the produced heterodimers and, to a much lesser extent, homodimers of BMP-2, but not BMP-6 or -7. Data given are (a) the median and interquartile range (IQR) and (b) the mean \pm SD from 3 independent donors; measurements were performed in duplicate. ${ }^{*}=$ significantly different from the other pBMP conditions. 
mouse BMPs. BMP-2 was detected in all groups and appeared to be mainly present in and directly around cells aligned to the BCP scaffold (Fig. 8). Furthermore, positive cells were present in the tibia control samples and in and around cells aligning to the newly formed bone (results not shown), indicating cross reactivity with endogenous BMP-2. The expression of BMP-2 varied among the individual conditions and was most obvious in the pBMP-2 and pBMP-2/7 conditions. BMP-7 was not detected in the control and pBMP-2 condition. Positive cells were only observed in the pBMP-7 and pBMP-2/7 conditions (Fig. 8).

\section{Discussion}

Non-viral delivery of plasmid DNA encoding BMP-2 together with BMP- 6 or -7 resulted in the formation of BMP heterodimers in recipient MSCs. An ex vivo method for delivering gene constructs into MSCs using pDNA was optimised and showed that codelivery of $\mathrm{pBMP}-2 / 6$ and $\mathrm{pBMP}-2 / 7$ prevailed over single $\mathrm{pBMP}$ delivery, regarding in vitro differentiation and in vivo bone formation.

BMP-2/6 and BMP-2/7 heterodimers were formed upon non-viral co-expression of pBMP-2/6 and pBMP-2/7, as shown by sandwich ELISAs. Both heterodimers were biologically active, as suggested by the increased differentiation and bone formation in the co-transfection conditions, where two heterodimers of BMP-2/6 and BMP-2/7 were formed along with their respective homodimers. It remained uncertain to which extend homodimers and heterodimers were present in one cell. BMP-7 detection was evidently lower in the co-delivery

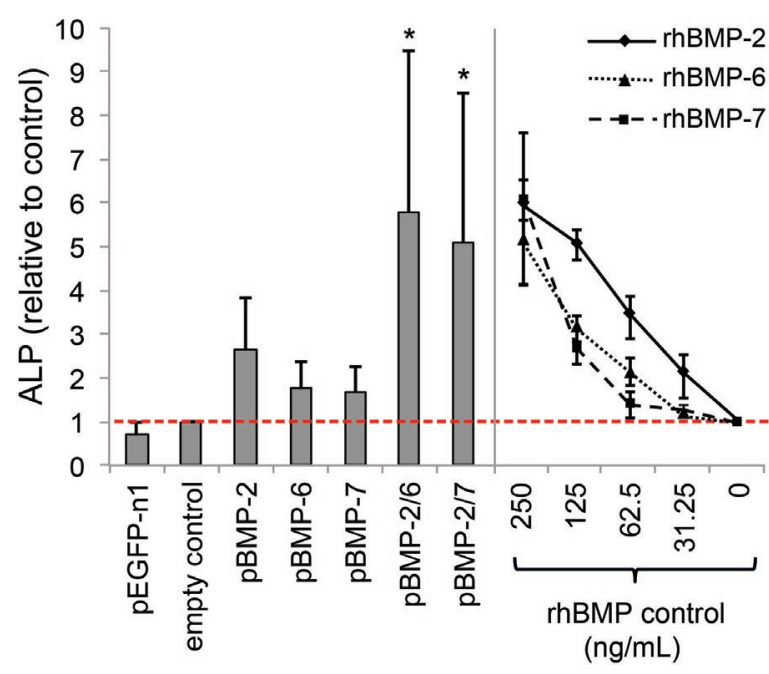

Fig. 4. Bioactivity of produced BMPs. ALP assay of ATDC reporter cells was performed after stimulation with conditioned medium from MSCs transfected as indicated. ALP activation is depicted in fold change relative to empty plasmid control. Results show mean \pm SD for $n=4$ donors. ${ }^{*}=$ significantly different from all other conditions except pBMP-2 and other co-delivery condition. condition: less than a third with respect to the homodimer condition. This effect was less apparent in the other conditions. Despite the lower protein content, the osteogenic differentiation in vitro and bone formation in vivo were increased in all cases of co-delivery of different BMP isoforms, leading to the conclusion that the heterodimers had a stronger biological activity than the corresponding homodimers, which is in line with earlier findings (Israel et al., 1996; Valera et al., 2010; Visser et al., 2015; Zachos et al., 2006). Compared to previous nonviral gene delivery work, which mainly focuses on combining pBMP-2 and pBMP-7 (Feichtinger et al., 2014; Kawai et al., 2009), it was shown that non-viral co-delivery of BMP-2/6 had comparable beneficial effects on bone formation.

To increase heterodimer production further, BMP coding sequences are combined in one vector, either separated by an intra ribosomal entry site or using separate promoters (Feichtinger et al., 2014). However, this results in lower downstream expression, competition in the CMV promoter region and lower heterodimer production (Feichtinger et al., 2014; Kawai et al., 2009). Therefore, co-delivery of separate plasmids remains an effective strategy (Kaito et al., 2013; Zhu et al., 2006). Alternative promoters that improve expression yields in adult stem cells may further enhance heterodimer production (Wen et al., 2014).

The mechanism underlying the increased biological activity of heterodimeric BMPs is not yet fully elucidated (Sun et al., 2012). BMPs use a common signal transduction pathway involving type I and II cell surface receptors. The binding of BMP to the receptor activates the SMAD signalling pathway (Nohe et al., 2004). BMP-2 has a high affinity for the bone morphogenetic protein receptor (BMPR) IA/ IB (ALK3 and ALK6), whereas BMP-6 and BMP-7 show high affinity for the activin A receptor, type I (ACVR, ALK2) (Miyazono et al., 2010). The increased bioactivity of the cells to which the BMP-2/6 and -2/7

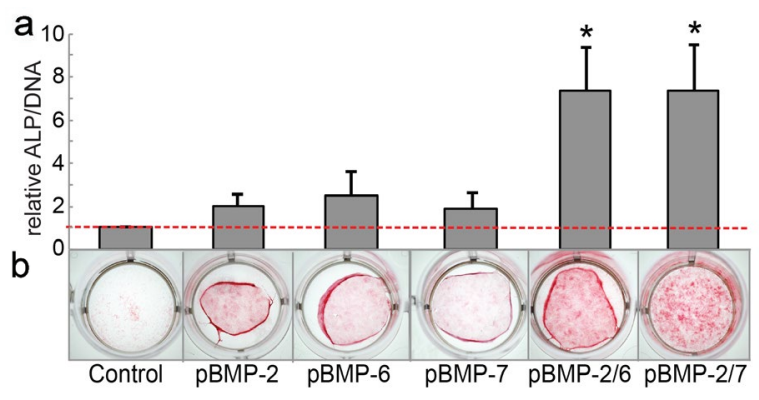

Fig. 5. Osteogenic differentiation of MSCs overexpressing pBMP. (a) ALP levels of MSCs overexpressing BMP genes relative to control. * = significantly different from all other conditions except the other co-delivery condition. (b) Representative qualitative alizarin red staining image for calcium deposition at day 20. Results represent mean \pm SD for $n=4$ donors. 

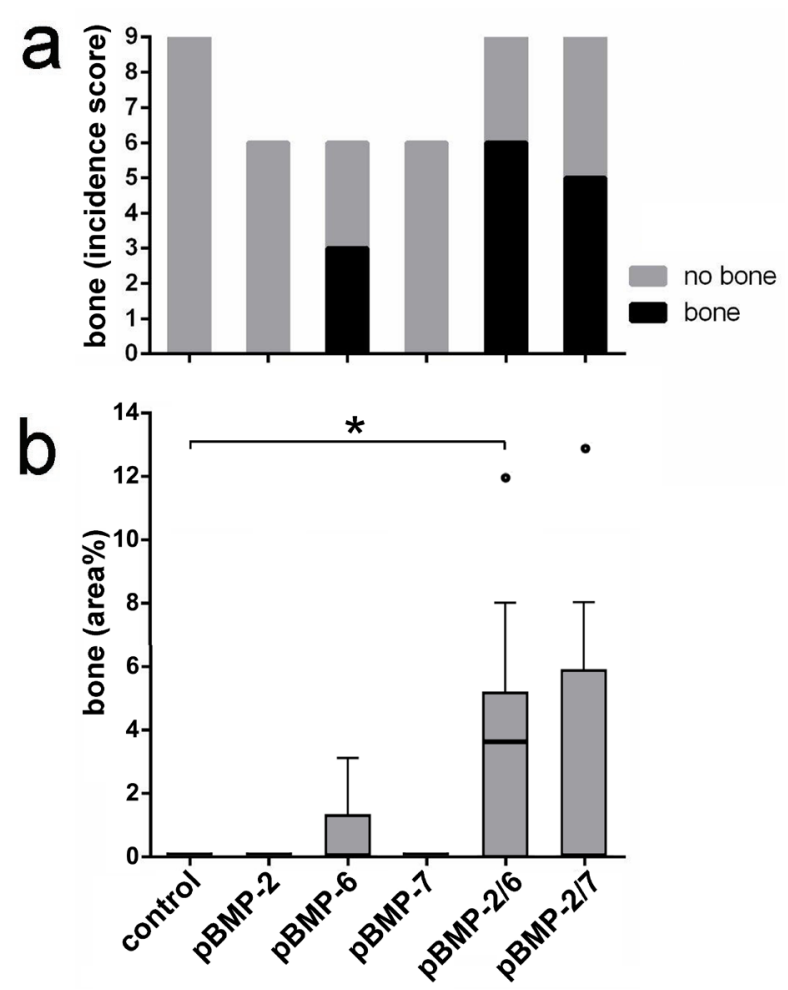

Fig. 6. Frequency plot and quantification of bone formation in mice. (a) Frequency plot showing the incidence of the bone within the construct boundaries. (b) Bone formation expressed as bone contact percentage. The results are represented as median and IQR. ${ }^{*}=$ significantly different from the control condition. heterodimers bind can be explained in three ways or a combination of these: first, the affinity for both receptors mentioned above combined, causing a greater SMAD activation (Isaacs et al., 2010; Valera et al., 2010); second, the signals generated by the heterodimers led to the up-regulation of the BMP receptor gene(s), such as the BMPR2 gene (Valera et al., 2010); third, heterodimeric and homodimeric BMPs differed in their ability to regulate the synthesis of BMP inhibitors and/or were differentially affected by these inhibitors. The BMP-2/7 heterodimer is resistant to noggin and is a weaker inducer of noggin as compared with homodimeric BMPs (Zhu et al., 2006).

The absence of bone in the BMP-2 and BMP7 single conditions was unexpected (Fig. 6), as implantation of goat MSCs results in bone formation in similar models (Geuze et al., 2010). Apart from inter-experimental variations, mainly attributed to the differences between supplied animal groups, the cause might be attributed to the nucleofection procedure. Although it was noted that in vitro the transfected cells proliferated and differentiated normally, nucleofection possibly influenced cell engraftment and performance upon implantation. In vivo, the total amount of BMP protein produced might have been below the threshold for bone formation or the timing of BMP release was inadequate to induce bone formation, despite evidence that produced BMP was present after 5 weeks in the BMP-2 and BMP-7 conditions.
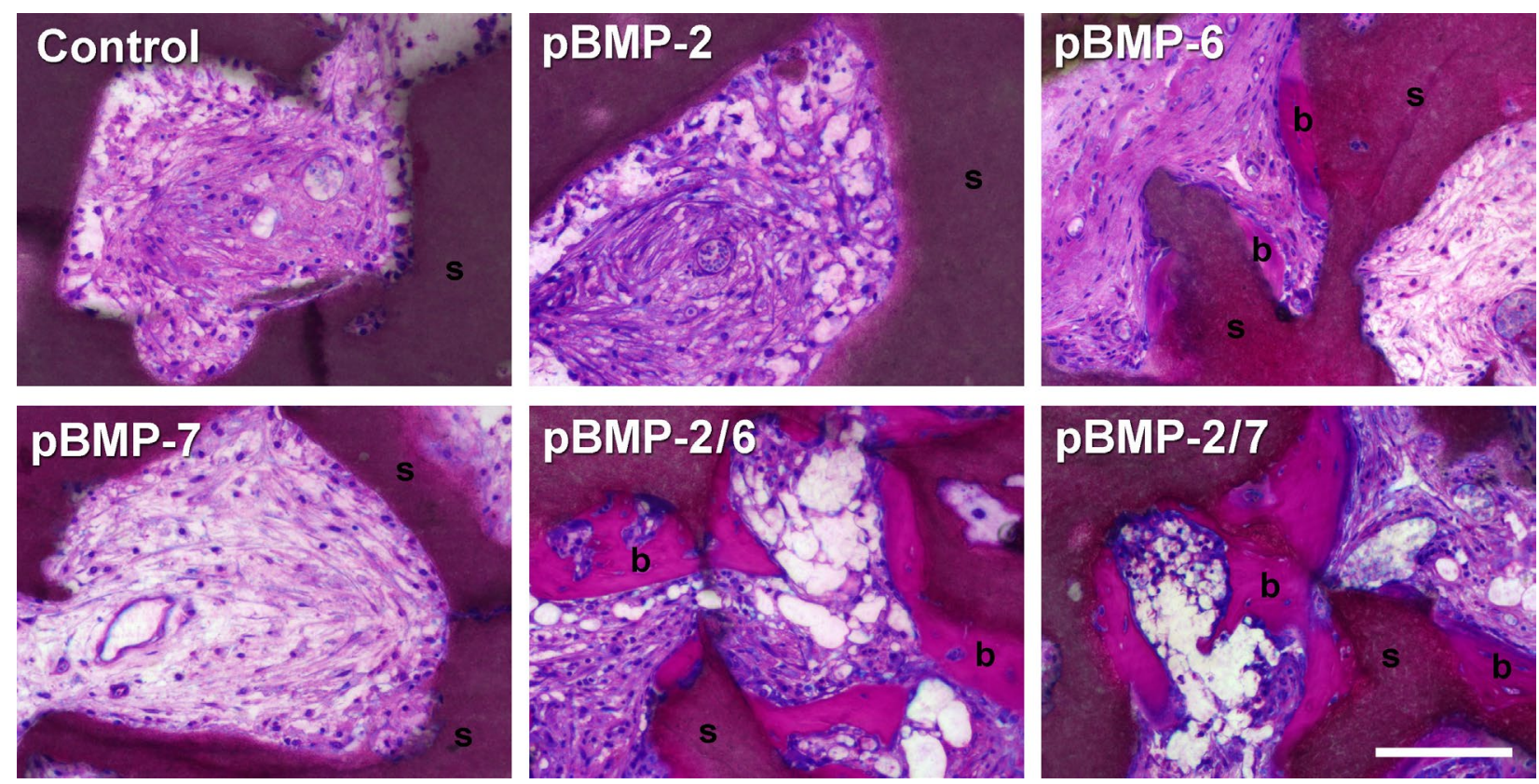

Fig. 7. Tissue ingrowth and bone formation after 2 and 5 weeks in vivo. Images show sections stained with basic fuchsin and methylene blue and containing ceramic scaffolds seeded with MSCs overexpressing BMPs. A representative image of each group is shown. Complete tissue ingrowth could be observed with frequent presence of blood vessels. No signs of fibrous capsule formation or immune responses were seen. In the pBMP-2/6, pBMP-2/7 and pBMP-6 conditions, bone formation was observed, with lamellar bone positioned at the ceramic scaffold surface. Sporadic bone marrow was observed in the pBMP-2/6 and pBMP-2/7 conditions. $s=$ scaffold; $b=$ bone. Scale bar $=100 \mu \mathrm{m}$. 

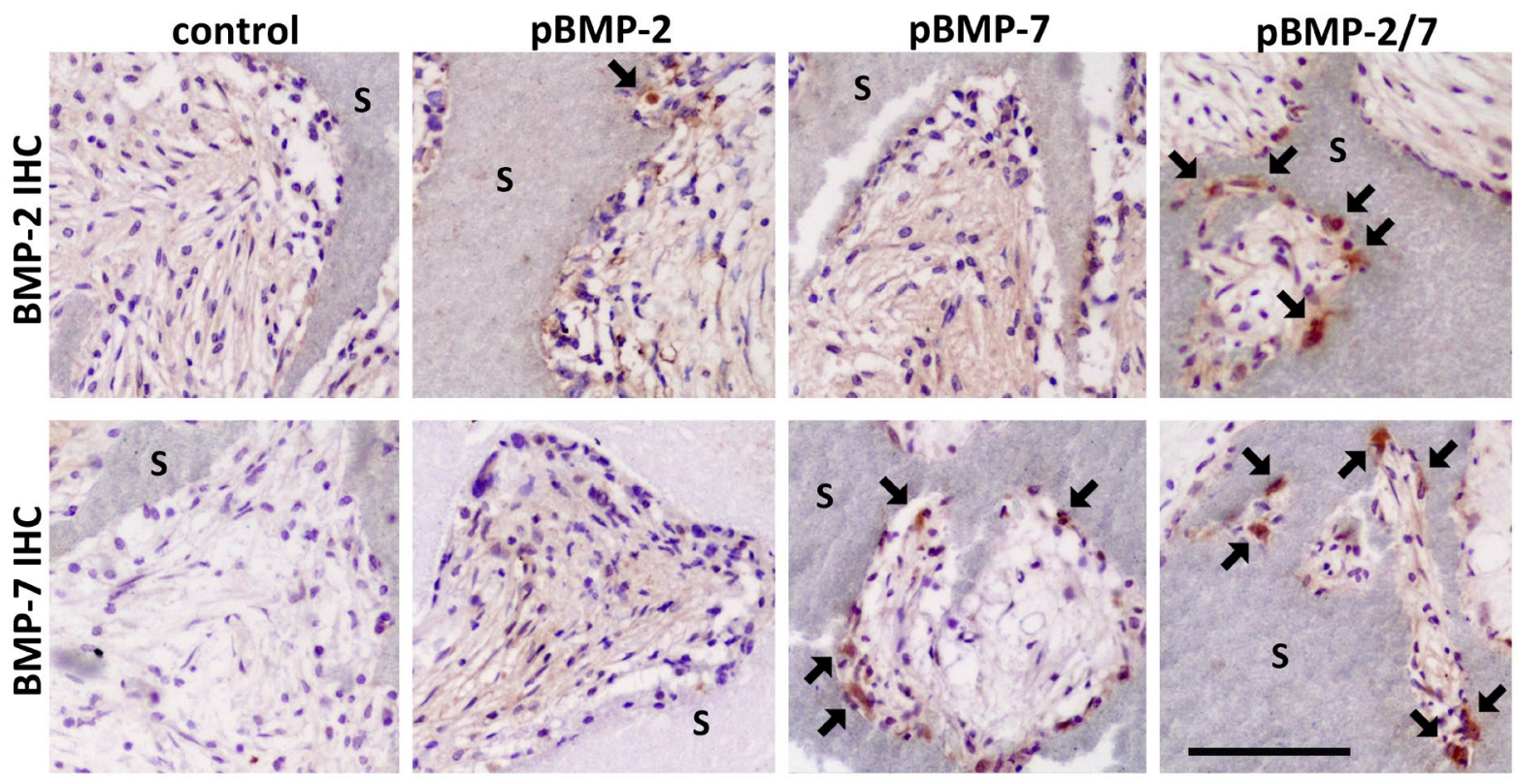

Fig. 8. Identification of BMP-expressing cells within construct boundaries. A representative image of the BMP-2 (upper row) and BMP-7 (lower row) immunohistochemistry is shown for each group. In the conditions where bone was present, images of areas away from the bone (showing abundant BMP presence) were taken. BMP in brown, as indicated with arrows. BMP-2 was found in all conditions, mainly present in and directly around cells that were aligned to the ceramic scaffold. The number of positive regions and intensity of BMP-2 staining varied among the individual conditions, but was most obvious in the pBMP-2 and pBMP-2/7 conditions. BMP-7 was not seen in every sample. $\mathrm{s}=$ scaffold. Scale bar $=100 \mu \mathrm{m}$.

This nucleofection strategy, with MSCs overexpressing BMPs, raised some other considerations. The ratio of homodimers and heterodimers produced by the same cell cannot be controlled. Despite the indications that the heterodimer formation in case of co-delivery was very efficient, it was presumed that also homodimers were formed in the same cells. Under conditions of saturated protein production, this lowered the maximal attainable BMP activity. By controlling the number of transfected cells, overdosing of BMP was prevented, which was an advantage. Due to the single-hit nature of this transfection method, gene expression was transient, lasting at most 2 weeks in vitro and possibly longer in vivo due to decreased proliferation rate. A system that allows renewed uptake of plasmid DNA, such as seen for some geneactivated matrices, could prolong the gene expression period, if necessary (Loozen et al., 2015). Lastly, an important issue is the use of easily transfectable MSCs, bringing either autologous or allogeneic strategies within reach.

The electroporation procedure is relatively harsh and the implanted cells may not survive for a very long time under conditions of limited vascularisation. Using gene-marked MSCs, long-term engraftment in the defect area and actual bone production by the transduced cells, along with the host cells are observed in small animal models (Geuze et al., 2010). Other studies show that BMP-2-transduced MSCs can function as a temporary delivery vehicle, stimulating host cells to form new bone (Gugala et al., 2003) and finally disappearing from the implant area (Pensak et al., 2015). With respect to clinical translation, it would be interesting to further elucidate the contribution and fate of BMP-producing cells in larger animal models.

In conclusion, simultaneous delivery of pBMP-2 and pBMP- 6 or -7 resulted in heterodimer formation, beneficial for induction of osteogenic differentiation and subsequent bone formation when compared to BMP homodimers.

\section{Acknowledgements}

We would like to thank Prof. Dr P. ten Dijke (Leiden University Medical Centre) for providing the BMP-6 cDNA. This work was supported by a grant from the Dutch government to the Netherlands Institute for Regenerative Medicine (NIRM, grant No. FES0908). This study was also funded by the Anna Fonds/NOREF. JA was supported by the Dutch Arthritis Foundation.

\section{References}

Asatrian G, Pham D, Hardy WR, James AW, Peault B (2015) Stem cell technology for bone regeneration: current status and potential applications. Stem Cells Cloning 8: 39-48. 
Aslan H, Zilberman Y, Arbeli V, Sheyn D, Matan Y, Liebergall M, Li JZ, Helm GA, Gazit D, Gazit Z (2006) Nucleofection-based ex vivo nonviral gene delivery to human stem cells as a platform for tissue regeneration. Tissue Eng 12: 877-889.

Becquart P, Cambon-Binder A, Monfoulet LE, Bourguignon M, Vandamme K, Bensidhoum M, Petite H, Logeart-Avramoglou D (2012) Ischemia is the prime but not the only cause of human multipotent stromal cell death in tissue-engineered constructs in vivo. Tissue Eng Part A 18: 2084-2094.

Bishop GB, Einhorn TA (2007) Current and future clinical applications of bone morphogenetic proteins in orthopaedic trauma surgery. Int Orthop 31: 721727.

Dickens S, Van den Berge S, Hendrickx B, Verdonck K, Luttun A, Vranckx JJ (2010) Nonviral transfection strategies for keratinocytes, fibroblasts, and endothelial progenitor cells for ex vivo gene transfer to skin wounds. Tissue Eng Part C Methods 16: 1601-1608.

Dupont KM, Sharma K, Stevens HY, Boerckel JD, Garcia AJ, Guldberg RE (2010) Human stem cell delivery for treatment of large segmental bone defects. Proc Natl Acad Sci U S A 107: 3305-3310.

Evans CH, Huard J (2015) Gene therapy approaches to regenerating the musculoskeletal system. Nat Rev Rheumatol 11: 234-242.

Feichtinger GA, Hacobian A, Hofmann AT, Wassermann K, Zimmermann A, van Griensven M, Redl H (2014) Constitutive and inducible coexpression systems for non-viral osteoinductive gene therapy. Eur Cell Mater 27: 166-184.

Flanagan M, Gimble JM, Yu G, Xia X, Bunnell BA, Li S (2012) Competitive DNA transfection formulation via electroporation for human adipose stem cells and mesenchymal stem cells. Biol Proced Online 14: 7.

Gaspar V, de Melo-Diogo D, Costa E, Moreira A, Queiroz J, Pichon C, Correia I, Sousa F (2015) Minicircle DNA vectors for gene therapy: advances and applications. Expert Opin Biol Ther 15: 353-379.

Gautschi OP, Frey SP, Zellweger R (2007) Bone morphogenetic proteins in clinical applications. ANZ J Surg 77: 626-631.

Geiger M, Li RH, Friess W (2003) Collagen sponges for bone regeneration with rhBMP-2. Adv Drug Deliv Rev 55: 1613-1629.

Geuze RE, Everts PA, Kruyt MC, Verbout AJ, Alblas J, Dhert WJ (2009) Orthotopic location has limited benefit from allogeneic or autologous multipotent stromal cells seeded on ceramic scaffolds. Tissue Eng Part A 15: 3231-3239.

Geuze RE, Prins HJ, Oner FC, van der Helm YJ, Schuijff LS, Martens AC, Kruyt MC, Alblas J, Dhert WJ (2010) Luciferase labeling for multipotent stromal cell tracking in spinal fusion versus ectopic bone tissue engineering in mice and rats. Tissue Eng Part A 16: 3343-3351.

Grayson WL, Bunnell BA, Martin E, Frazier T, Hung BP, Gimble JM (2015) Stromal cells and stem cells in clinical bone regeneration. Nat Rev Endocrinol 11: 140-150.

Gugala Z, Olmsted-Davis EA, Gannon FH, Lindsey RW, Davis AR (2003) Osteoinduction by ex vivo adenovirus-mediated BMP2 delivery is independent of cell type. Gene Ther 10: 1289-1296.

Isaacs MJ, Kawakami Y, Allendorph GP, Yoon BH, Izpisua Belmonte JC, Choe S (2010) Bone morphogenetic protein-2 and -6 heterodimer illustrates the nature of ligand-receptor assembly. Mol Endocrinol 24: 1469-1477.

Israel DI, Nove J, Kerns KM, Kaufman RJ, Rosen V, Cox KA, Wozney JM (1996) Heterodimeric bone morphogenetic proteins show enhanced activity in vitro and in vivo. Growth Factors 13: 291-300.

Kaito T, Johnson J, Ellerman J, Tian H, Aydogan M, Chatsrinopkun M, Ngo S, Choi C, Wang JC (2013) Synergistic effect of bone morphogenetic proteins 2 and 7 by ex vivo gene therapy in a rat spinal fusion model. J Bone Joint Surg Am 95: 1612-1619.

Kang Q, Sun MH, Cheng H, Peng Y, Montag AG, Deyrup AT, Jiang W, Luu HH, Luo J, Szatkowski JP, Vanichakarn P, Park JY, Li Y, Haydon RC, He TC (2004) Characterization of the distinct orthotopic bone-forming activity of $14 \mathrm{BMPs}$ using recombinant adenovirus-mediated gene delivery. Gene Ther 11: 1312-1320.

Kawai M, Maruyama H, Bessho K, Yamamoto H, Miyazaki J, Yamamoto T (2009) Simple strategy for bone regeneration with a BMP-2/7 gene expression cassette vector. Biochem Biophys Res Commun 390: 1012-1017.

Kayabasi GK, Aydin RS, Gumusderelioglu M (2013) In vitro chondrogenesis by BMP6 gene therapy. J Biomed Mater Res A 101: 1353-1361.

Kruyt M, De Bruijn J, Rouwkema J, Van Bliterswijk C, Oner C, Verbout A, Dhert W (2008) Analysis of the dynamics of bone formation, effect of cell seeding density, and potential of allogeneic cells in cell-based bone tissue engineering in goats. Tissue Eng Part A 14: 1081-1088.

Kruyt MC, Dhert WJ, Oner C, van Blitterswijk CA, Verbout AJ, de Bruijn JD (2004) Optimization of bone-tissue engineering in goats. J Biomed Mater Res B Appl Biomater 69: 113-120.

Li H, Li JZ, Pittman DD, Amalfitano A, Hankins GR, Helm GA (2006) Comparison of osteogenic potentials of human rat BMP4 and BMP6 gene therapy using [E1-] and [E1-,E2b-] adenoviral vectors. Int J Med Sci 3: 97-105.

Little SC, Mullins MC (2009) Bone morphogenetic protein heterodimers assemble heteromeric type I receptor complexes to pattern the dorsoventral axis. Nat Cell Biol 11: 637-643.

Loozen L, Helm van der YJ, Oner FC, Dhert W, Kruyt MC, Alblas J (2015) Bone morphogenetic protein-2 non-viral gene therapy in a goat iliac crest model for bone formation. Tissue Eng Part A 21: 1672-1679.

Loozen LD, Wegman F, Oner FC, Dhert WJA, Alblas J (2013) Porous bioprinted constructs in BMP-2 
non-viral gene therapy for bone tissue engineering. J Mater Chem B 1: 6619-6626.

Miyazono K, Kamiya Y, Morikawa M (2010) Bone morphogenetic protein receptors and signal transduction. J Biochem 147: 35-51.

Mizrahi O, Sheyn D, Tawackoli W, Kallai I, Oh A, Su S, Da X, Zarrini P, Cook-Wiens G, Gazit D, Gazit $\mathrm{Z}$ (2013) BMP-6 is more efficient in bone formation than BMP-2 when overexpressed in mesenchymal stem cells. Gene Ther 20: 370-377.

Morimoto T, Kaito T, Matsuo Y, Sugiura T, Kashii M, Makino T, Iwasaki M, Yoshikawa H (2015) The bone morphogenetic protein-2/7 heterodimer is a stronger inducer of bone regeneration than the individual homodimers in a rat spinal fusion model. Spine J 15: 1379-1390.

Mueller TD, Nickel J (2012) Promiscuity and specificity in BMP receptor activation. FEBS Lett 586: 1846-1859.

Nakajima S, Naruto T, Miyamae T, Imagawa T, Mori M, Nishimaki S, Yokota S (2009) Interleukin-6 inhibits early differentiation of ATDC 5 chondrogenic progenitor cells. Cytokine 47: 91-97.

Nohe A, Keating E, Knaus P, Petersen NO (2004) Signal transduction of bone morphogenetic protein receptors. Cell Signal 16: 291-299.

Osawa K, Okubo Y, Nakao K, Koyama N, Bessho K (2010) Osteoinduction by repeat plasmid injection of human bone morphogenetic protein-2. J Gene Med 12: 937-944.

Papakostidis C, Kontakis G, Bhandari M, Giannoudis PV (2008) Efficacy of autologous iliac crest bone graft and bone morphogenetic proteins for posterolateral fusion of lumbar spine: a meta-analysis of the results. Spine (Phila Pa 1976) 33: E680-692.

Pensak M, Hong S, Dukas A, Tinsley B, Drissi $\mathrm{H}$, Tang A, Cote M, Sugiyama O, Lichtler A, Rowe D, Lieberman JR (2015) The role of transduced bone marrow cells overexpressing BMP-2 in healing critical-sized defects in a mouse femur. Gene Ther 22: 467-475.

Poynton AR, Lane JM (2002) Safety profile for the clinical use of bone morphogenetic proteins in the spine. Spine (Phila Pa 1976) 27: S40-48.

Sanz L, Compte M, Guijarro-Munoz I, AlvarezVallina L (2012) Non-hematopoietic stem cells as factories for in vivo therapeutic protein production. Gene Ther 19: 1-7.

Sheyn D, Pelled G, Zilberman Y, Talasazan F, Frank JM, Gazit D, Gazit Z (2008) Nonvirally engineered porcine adipose tissue-derived stem cells: use in posterior spinal fusion. Stem Cells 26: 10561064.

Sun P, Wang J, Zheng Y, Fan Y, Gu Z (2012) BMP2/7 heterodimer is a stronger inducer of bone regeneration in peri-implant bone defects model than BMP2 or BMP7 homodimer. Dent Mater J 31: 239-248.

Valera E, Isaacs MJ, Kawakami Y, Izpisua Belmonte JC, Choe S (2010) BMP-2/6 heterodimer is more effective than BMP-2 or BMP-6 homodimers as inductor of differentiation of human embryonic stem cells. PLoS One 5: e11167.

van Gaalen SM, Kruyt MC, Geuze RE, de Bruijn JD, Alblas J, Dhert WJA (2010) Use of fluorochrome labels in in vivo bone tissue engineering research. Tissue Eng Part B Rev 16: 209-217.

Virk MS, Sugiyama O, Park SH, Gambhir SS, Adams DJ, Drissi H, Lieberman JR (2011) "Same day" ex-vivo regional gene therapy: a novel strategy to enhance bone repair. Mol Ther 19: 960-968.

Visser R, Bodnarova K, Arrabal PM, Cifuentes M, Becerra J (2015) Combining bone morphogenetic proteins-2 and -6 has additive effects on osteoblastic differentiation in vitro and accelerates bone formation in vivo. J Biomed Mater Res A 104:178-185.

Vukicevic S, Grgurevic L (2009) BMP-6 and mesenchymal stem cell differentiation. Cytokine Growth Factor Rev 20: 441-448.

Wen S, Zhang H, Li Y, Wang N, Zhang W, Yang $\mathrm{K}$, Wu N, Chen X, Deng F, Liao Z, Zhang J, Zhang Q, Yan Z, Liu W, Zhang Z, Ye J, Deng Y, Zhou G, Luu HH, Haydon RC, Shi LL, He TC, Wei G (2014) Characterization of constitutive promoters for piggyBac transposon-mediated stable transgene expression in mesenchymal stem cells (MSCs). PLoS One 9: e94397.

Zachos TA, Shields KM, Bertone AL (2006) Genemediated osteogenic differentiation of stem cells by bone morphogenetic proteins-2 or -6. J Orthop Res 24: 1279-1291.

Zhu W, Kim J, Cheng C, Rawlins BA, BoachieAdjei O, Crystal RG, Hidaka C (2006) Noggin regulation of bone morphogenetic protein (BMP) 2/7 heterodimer activity in vitro. Bone 39: 61-71.

Zhu W, Rawlins BA, Boachie-Adjei O, Myers ER, Arimizu J, Choi E, Lieberman JR, Crystal RG, Hidaka C (2004) Combined bone morphogenetic protein-2 and -7 gene transfer enhances osteoblastic differentiation and spine fusion in a rodent model. J Bone Miner Res 19: 2021-2032.

\section{Discussion with Reviewers}

Georg Feichtinger: There is increasing evidence that, for some therapeutic transgenes, the use of speciesspecific sequences (in the corresponding animal model) influences bioactivity, immune responses and/or bioavailability of the product and subsequent therapeutic outcome. Do you expect such an effect for the employed BMP sequences and how would the combination of human and murine sequences affect the therapeutic success in a murine model?

Authors: The sequences of the BMP isoforms used have a high level of conservation, both at nucleotide and amino acid level, among different species. The murine and human BMP-2 sequences are identical in the mature region (Dickinson et al., 1990, additional reference). The murine BMP- 6 and BMP-7 sequences are also similar to the human forms, with only 1 
(BMP-7) or 2 (BMP-6) amino acid differences in the 7-cysteine region; BMP-6 has 5 differences in the basic amino-terminal domain, BMP-7 has only 2 (Ozkaynak et al., 1991, additional reference).

A comparison of vectors containing human or rodent BMP-6 demonstrates identical osteogenic activities in both immunodeficient and immunocompetent rats (Li et al., 2006). Similar human and rodent BMP- 6 gene products activities are found in all models ( $\mathrm{Li}$ et al., 2006). These results indicate that the amount and source of the BMP cDNA are not the main factors influencing bioactivity in immunocompetent animals.

Because isolated BMP-BMPR affinity studies between species are not available, it is impossible to rule out species-specific differences between mouse and human sequences used. However, it is conceivable that mouse and human BMP gene products are interchangeable, based on many studies showing similar activities in several immediate and long-term readouts (Li et al., 2006; Wu et al., 2016, additional reference).

Georg Feichtinger: The authors stated that BMP co-expression strategies using one plasmid coexpression system for both factors can be impaired by competition/interference at the promoter region and, therefore, propose the use of individual plasmids for each factor. What effect on heterodimer formation rate could be anticipated if two plasmids have to be delivered individually? How could abundant co-transfection of target cells be ensured and how could this be potentially influenced by the chosen gene transfer modality?

Authors: Co-transfection of target cells with two plasmids occurs independently of the chosen transfection method. Combining two genes in one vector each under their own promoter or by delivery of a polycistronic messenger (using internal ribosome entry site) ensures co-delivery, but not equal expression.

Separate promoter regions in one cassette show lower expression efficacy in co-expression systems as compared to separate vectors (Kawai et al., 2009; Feichtinger et al., 2014). As an explanation, transcriptional interference of CMV-enhancer elements competing for transcription initiation is suggested (Kawai et al., 2009; Feichtinger et al., 2014). The most common strategy for co-expressing multiple genes from a single vector is the use of an internal ribosomal entry site sequence (Wong et al., 2002, additional reference). However, a wellknown and severe disadvantage of this method is the expression level of the downstream gene, being usually significantly less than the upstream gene.

Given that BMP-heterodimer formation relies on protein folding and disulphide bridge formation during translation, the simultaneous presence of two messengers is theoretically preferable. Co-delivery of two separate plasmids has proven the most effective strategy to date (Kawai et al., 2006, additional reference). Production of BMP homodimers cannot be avoided using either single or double plasmids strategies and, therefore, assessment of the ratio of homo- and heterodimers remains necessary.

Ryan Porter: The authors mentioned in the Discussion that, using the nucleofection strategy presented here, the ratio of homo- to heterodimers produced by the same cell cannot be controlled. However, as stated in the manuscript, the efficiency of heterodimer formation by the modified cells would likely impact the overall therapeutic efficacy of the approach. How might future iterations of this genetic engineering approach increase the efficiency of the heterodimer formation? If a solution is unclear at this time, what current gaps in knowledge (e.g. BMP posttranslational processing) must first be filled?

Authors: Several strategies to control heterodimer formation are reported, including combining the two vectors in a single cassette with different promoter regions or with a single promoter but applying a polycistronic messenger. Despite the effort, both strategies are inferior to combining two separate vectors (Feichtinger et al., 2014; Kawai et al., 2009; Wong et al., 2002, additional reference).

One other option might be to produce the two chains of the BMP heterodimer as a single chain, separated by a protease sequence, such as a T2A site. Likely, the proteins would fold post-translationally and couple to the dimeric counterpart.

Optimised nuclear entry and stabilisation of the messenger would alternatively lead to more efficient heterodimer formation.

Ryan Porter: This study has focused on stimulating bone formation by direct osteogenesis using the BMP-2/7 and BMP-2/6 heterodimers. Recent studies demonstrate the efficacy of directing chondrogenesis and endochondral bone formation for bone defect repair. Does the current literature - or your own experimental observations - suggest that one or both heterodimers might direct an endochondral repair pathway?

Authors: Signs of endochondral bone formation are observed when using ceramic scaffolds loaded with BMP-2 (Wegman et al., 2013, additional reference); however, in this study, remnants of intermediate cartilage matrix were not observed. Analysis at earlier time points may give more insight into the ability of BMP heterodimers to induce endochondral bone formation. In vitro, hypertrophic MSCs, as a result of BMP heterodimer induction, were not observed.

Literature shows that heterodimers play a role in the endochondral pathway: BMP-2/6 heterodimers are capable of inducing the chondrogenic pathway in limb bud MSCs and osteogenic differentiation in a pre-osteoblast cell line (Isaacs et al., 2010).

Ryan Porter: Since the strategy outlined here relies on ex vivo manipulation of culture-expanded cells, what might be the translational considerations of 
substituting nucleofection with transduction using a non-integrating, recombinant viral vector, such as adeno-associated virus or a non-integrating lentiviral vector?

Authors: The aim is to work towards a clinical application of gene delivery: safety, duration of the procedure and costs need to be addressed. Application of viral sequences, even if they do no integrate, is considered less safe than plasmid-based transfection, such as nucleofection. Furthermore, viral transduction procedures are longer (hours vs. minutes) and require more costly safety measures.

\section{Additional References}

Dickinson ME, Kobrin MS, Silan CM, Kingsley DM, Justice MJ, Miller DA, Ceci JD, Lock LF, Lee A, Buchberg AM, Siracusa LD, Lyons KM, Derynck R, a, Hogan BLM, Copeland NG, Jenkins NA (1990) Chromosomal localization of seven members of the murine TGF-beta superfamily suggests close linkage to several morphogenetic mutant loci. Genomics 6 : 505-520.

Kawai M, Bessho K, Maruyama H, Miyazaki J and Yamamoto T (2006) Simultaneous gene transfer of bone morphogenetic protein (BMP) -2 and BMP-7 by in vivo electroporation induces rapid bone formation and BMP-4 expression. BMC Musculoskelet Disord 7: 62 .

Ozkaynak E, Schnegelsberg PN and Oppermann H (1991) Murine osteogenic protein (OP-1): high levels of mRNA in kidney. Biochem Biophys Res Commun 179: 116-123.

Wegman F, van der Helm Y, Öner FC, Dhert WJ, Alblas J (2013) Bone morphogenetic protein-2 plasmid DNA as a substitute for bone morphogenetic protein-2 protein in bone tissue engineering. Tissue Eng Part A 19: 2686-92

Wong ET, Ngoi SM and Lee CG (2002) Improved co-expression of multiple genes in vectors containing internal ribosome entry sites (IRESes) from human genes. Gene Ther 9: 337-344.

Wu M, Chen G, Li YP (2016) TGF- $\beta$ and BMP signaling in osteoblast, skeletal development, and bone formation, homeostasis and disease. Bone Res. 4: 16009 .

Editor's note: The Scientific Editor responsible for this paper was Chris Evans. 